\title{
Disopyramide stress test: a sensitive and specific tool for predicting impending high degree atrioventricular block in patients with bifascicular block
}

\author{
Anders Englund, Lennart Bergfeldt, Mårten Rosenqvist
}

\begin{abstract}
Objective-To study the value of intravenous disopyramide as part of an invasive electrophysiological study in predicting impending high degree atrioventricular block in patients with bifascicular block.

Design-An invasive electrophysiological study was performed in the basal state and after the infusion of disopyramide (2 $\mathrm{mg} / \mathrm{kg}$ body weight). The progression to high degree atrioventricular block was assessed by bradycardia-detecting pacemakers or repeated 12-lead electrocardiogram recordings, or both.

Patients-73 patients with bifascicular block were included, of whom 25 had a history of unexplained syncope. The remaining 48 patients had no arrhythmia related symptoms and were included as controls. All patients had an ejection fraction of $>35 \%$.

Results-After a mean follow up of 23 months, seven patients in the syncope group and three in the non-syncope group had a documented high degree atrioventricular block or pacemaker-detected bradycardia of $\leqslant 30$ beats/min for $\geqslant 6 \mathrm{~s}$. The sensitivity of the disopyramide test was $71 \%$ and the specificity $98 \%$. The corresponding figures for an abnormal electrophysiological study in the basal state were $14 \%$ and $91 \%$, respectively.

Conclusions-The sensitivity of an invasive electrophysiological study in patients with bifascicular block and syncope can be markedly increased by the use of intravenous disopyramide. A positive test is a highly specific finding and warrants pacemaker implantation.
\end{abstract}

(Br Heart f 1995;74:650-655)

Keywords: disopyramide stress test, atrioventricular block, bifascicular block, electrophysiological study

Bifascicular block, defined as left bundle branch block or right bundle branch block with left anterior or posterior fascicular block, has a prevalence of between $1 \%$ and $1.5 \%$ in an adult population. ${ }^{1-3} \mathrm{Up}$ to $25 \%$ of patients with bifascicular block have a history of syncope $^{3}$ and the management of these patients is a common clinical problem. The overall yearly incidence of progression to high degree atrio- ventricular block is only $1-4 \%^{3-5}$ and the strategy of pacemaker implantation in all symptomatic patients can thus be questioned. No non-invasive test has been found to be useful in predicting subsequent high degree atrioventricular block, and an invasive electrophysiological study is often of limited value. ${ }^{4-7}$ Findings with a high specificity, such as an HV interval of $>100 \mathrm{~ms}$ and a His-Purkinje block during atrial pacing, are rare and hence have a low sensitivity. ${ }^{5}$

In order to increase the sensitivity of an electrophysiological study, a pharmacological stress test of the His-Purkinje system has been proposed, and ajmaline, ${ }^{910}$ procainamide, ${ }^{11-13}$ and disopyramide ${ }^{1415}$ have been used for this purpose. The clinical value of these tests has, however, not been well defined, primarily because of the lack of appropriate controls and the lack of sensitive tools for detecting intermittent high degree atrioventricular block.

The aim of this study was to evaluate prospectively the value of intravenous disopyramide as part of an invasive electrophysiological study in predicting impending high degree atrioventricular block in patients with bifascicular block.

\section{Methods}

PATIENTS

Between October 1991 and November 1993, 73 patients with bifascicular block were studied prospectively. Twenty five had a history of syncope, and 48 had not. Most of the patients in the syncope group were recruited from four casualty departments. Patients in whom significant brady- or tachyarrhythmias were found on a $24 \mathrm{~h}$ telemetry recording were excluded.

The control group was identified by using a computerised storage unit for 12-lead electrocardiograms. Patients under the age of 85 years with a bifascicular block were screened and asked to participate in the study. Twelve of these patients were found to have a history of syncopal attacks and were included in the syncope group. The remaining subjects had no history of syncope or presyncope, palpitations, or dizzy spells and formed the control group.

Before the electrophysiological study, a careful history was taken from all patients and they received a physical examination, a chest $x$ ray, and an echo Doppler examination, including assessment of the left ventricular ejection fraction, according to Simpson. ${ }^{16}$

Because of the negative inotropic effect of 
disopyramide, patients with an ejection fraction of $\leqslant 35 \%$ or uncompensated heart failure were not included.

\section{ELECTROPHYSIOLOGICAL STUDY}

This was performed in the postabsorptive unsedated state using three-electrode catheters, after the withdrawal of all antiarrhythmic medication for $\geqslant 5$ elimination half lives. The protocol included recording of conduction intervals, assessment of the cycle length at Wenckebach block during incremental atrial pacing, and right ventricular pacing at 100,120 , and 150 beats/min for $60 \mathrm{~s}$ before and after disopyramide. Disopyramide was given intravenously, $2 \mathrm{mg} / \mathrm{kg}$ body weight with a maximum dose of $150 \mathrm{mg}$, over a period of 5 min. Programmed ventricular stimulation was performed at baseline from two right ventricular sites with one to three extra stimuli at 100 and 150 beats/min.

The disopyramide test was considered positive under any of the following four circumstances ${ }^{14}$ : second or third degree His-Purkinje block during (1) sinus rhythm or (2) atrial pacing; or (3) after abruptly terminated ventricular pacing or (4) $\mathrm{HV}$ prolongation of $\geqslant 50 \%$.

\section{TREATMENT AND FOLLOW UP}

According to the study protocol all patients with a history of syncope were recommended for pacemaker implantation. The majority of the implanted pulse generators were VVI pacemakers with a bradycardia-detecting function. This device allows the disclosure of the number of episodes with a spontaneous rate $<30$ beats/min for $6 \mathrm{~s}$ by internal telemetry and has been shown to be a safe and sensitive tool for detecting atrioventricular block development. ${ }^{15} 17$ Patients in the non-syncope group were not treated unless the disopyramide test was positive. All patients were seen at the outpatient clinic after six weeks and thereafter, on the average, every sixth month.

\section{DEFINITIONS}

His-Purkinje block: second or third degree atrioventricular block located within or below the bundle of His. Left bundle branch block and right bundle branch block: standard definitions were used. ${ }^{18}$ Left anterior fascicular block: mean frontal QRS axis $<-30^{\circ}$. Left posterior fascicular block: mean frontal QRS axis $>+90^{\circ}$ in the absence of right ventricular hypertrophy. Syncope: sudden complete loss of consciousness and muscular tone with full spontaneous recovery. Sudden death: patients dying within $1 \mathrm{~h}$ of new symptoms or unexpectedly with no or stable symptoms or during sleep.

\section{STATISTICAL METHODS}

Descriptive statistics and graphical methods were used to characterise data. Fisher's exact test was used for comparisons of proportions. Comparisons of continuous variables were made using Student's $t$ test, after validation for normal distribution by the Shapiro-Wilk test. ${ }^{19}$ Sensitivity was defined in the syncope group as the number of patients with a positive test and high degree atrioventricular block or pacemaker detected bradycardia during follow up, or both, (true positives) divided by the total number of patients with high degree atrioventricular block or pacemaker detected bradycardia, or both. The specificity was defined in the non-syncope group as the number of patients with a negative test and no documented high degree atrioventricular block or pacemaker detected bradycardia during follow up (true negatives) divided by the total number of patients with no documented high degree atrioventricular block or pacemaker detected bradycardia. ${ }^{20}$ The Kaplan Meier method $^{21}$ was used for comparing patients with positive and negative disopyramide tests regarding the development of high degree atrioventricular block or pacemaker detected bradycardia during follow up. All analyses were performed using the statistical package of $J M P^{\circledR}$, version 3.0 (SAS Institute). A P value $<0.05$ was considered statistically significant.

\section{ETHICS}

The procedure of the electrophysiological study was explained in detail to each patient before inclusion and verbal consent was obtained, in accordance with the guidelines of the ethics committee of the Karolinska Hospital, which had approved the study.

\section{Results}

\section{STUDY GROUPS}

The two study groups were well matched with regard to demographic and clinical characteristics, ejection fraction, and type of bifascicular block (table 1).

BASAL STATE

There was no difference in any electrophysiological variable between the syncope and nonsyncope group in the basal state (table 2). Abnormalities in the sinus node, atrioventricular node, or His-Purkinje system, alone or in combination, were found in 10 patients $(40 \%)$ in the syncope group and 24 patients $(50 \%)$ in the non-syncope group (NS). A His-Purkinje block during atrial pacing was found in two patients, both in the non-syncope group.
BFB, bifascicular block; CHF, congestive heart failure; F, female; LBBB, left bundle branch block; LAFB, left anterior fascicular block; LPFB, left posterior fascicular block; $M$, male; MI, myocardial infarction; RBBB, right bundle branch block; VOC, valvar heart disease. No statistically significant differences were found. 
Table 2 Electrophysiological characteristics of patients with and without syncope in the basal state and after disopyramide infusion

\begin{tabular}{lcc}
\hline & $\begin{array}{c}\text { Syncope group } \\
(n=25)\end{array}$ & $\begin{array}{c}\text { No syncope group } \\
(n=48)\end{array}$ \\
\hline Basal state & & \\
CSNRT > 545 ms n (\%) & $2(8)$ & $10(21)$ \\
AVN-ERP > 420 ms n (\%) & $2(8)$ & $4(8)$ \\
Wenckebach point beats/min (range) & $167(121-226)$ & $157(103-204)$ \\
HV interval median ms (range) & $52(35-109)$ & $53(32-87)$ \\
HV interval > 70 ms n (\%) & $2(8)$ & $5(10)$ \\
His-Purkinje block at AP n (\%) & 0 & $2(4)$ \\
Monomorphic sustained VT n (\%) & $1(4)$ & $1(2)$ \\
After intravenous disopyramide & & \\
Positive test (\%) & $8(32)^{\star}$ & $4(8)$ \\
HV interval median ms (range) & $65(40-\infty)$ & $66(32-\infty)$ \\
HV difference mean \% & 25 & 25 \\
Wenckebach point beats/min (range) & $155(94-235)$ & $156(89-204)$ \\
\hline
\end{tabular}

$\mathrm{AP}$, atrial pacing; AVN-ERP, effective refractory period of the atrioventricular node at a basic drive of 100 beats/min; CSNRT, corrected sinus node recovery time; VT, ventricular tachycardia. ${ }^{\star} \mathrm{P}<0.02 v$ no syncope group; no other comparisons are statistically significant.

Sustained monomorphic ventricular tachycardia was induced in one syncope and one nonsyncope patient. Both had an otherwise normal electrophysiological study.

DISOPYRAMIDE TEST

The mean HV interval was prolonged by $25 \%$ $(P<0.001)$ in both groups $5 \mathrm{~min}$ after the end of disopyramide infusion (table 2). In total, 12 patients, eight in the syncope group (32\%) and four in the non-syncope group (8\%), had a positive disopyramide test $(P<0.02)$. Five patients had a positive test from all aspects, five had His-Purkinje block during atrial pacing, and two had a His-Purkinje block after ventricular pacing, which in one was combined with an $\mathrm{HV}$ prolongation of $\geqslant 50 \%$.

\section{SAFETY ASPECTS}

No patient had a fall in systolic blood pressure of $>40 \mathrm{~mm} \mathrm{Hg}$ from the baseline value. One patient had a symptomatic fall in systolic blood pressure from 120 to $85 \mathrm{~mm} \mathrm{Hg}$ which was successfully treated with saline infusion. All other patients were asymptomatic. All patients who had disopyramide induced complete atrioventricular block resumed 1:1 conduction within $2 \mathrm{~h}$. The ventricular escape rate ranged between 25 and 40 beats/min and temporary back up pacing was required in three patients.

TREATMENT AND FOLLOW UP

All syncope patients were recommended for pacemaker treatment, which was accepted by
20 and declined by five. Four patients in the non-syncope group with a positive disopyramide test had pacemakers implanted. Seventeen and three patients, respectively, received pacemakers with bradycardia detecting function.

During a mean follow up of 23 months (range 11-36), one patient died suddenly and five had syncopal attacks, of which two occurred in the non-syncope group (table 3 ). In none of these five patients did the electrophysiological study indicate an impending high degree atrioventricular block or inducible sustained monomorphic ventricular tachycardia, but two patients had a prolonged sinus node recovery time.

Six patients had documented high degree atrioventricular block during follow up, five in the syncope group and one in the non-syncope group. Two patients in each group had a pacemaker detected bradycardia but no documented high degree atrioventricular block. Thus 10 patients, seven in the syncope group $(28 \%)$ and three in the non-syncope group $(6 \%)(P<0.02)$, had either high degree atrioventricular block or bradycardia during follow up (table 4).

The two patients with inducible sustained monomorphic ventricular tachycardia were both treated with metoprolol on an empirical basis and the syncope patient also received a pacemaker. None had a syncope or documented arrhythmia during follow up.

SENSITIVITY AND SPECIFICITY OF THE BASELINE ELECTROPHYSIOLOGICAL STUDY OF THE DISTAL CONDUCTION SYSTEM

Only one of the seven patients in the syncope group with a documented high degree atrioventricular block or bradycardia during follow up had an $\mathrm{HV}$ interval of $>70 \mathrm{~ms}$, that is, a sensitivity of $14 \%$. Since no patient in the syncope group had a His-Purkinje block induced by atrial pacing, the sensitivity of this test was null. The specificity of these two findings was $91 \%$ and $100 \%$, respectively.

\section{SENSITIVITY AND SPECIFICITY OF THE} DISOPYRAMIDE TEST

The disopyramide test was positive in five of the seven patients who developed high degree atrioventricular block or bradycardia during follow up in the syncope group, that is, a sensitivity of $71 \%$. All patients with documented high degree atrioventricular block had a posi-

Table 3 Clinical and electrophysiological characteristics of patients with sudden death or syncope during follow up

\begin{tabular}{lllllllll}
\hline Sex/age & $\begin{array}{l}\text { History of } \\
\text { syncope }\end{array}$ & Event & Month & $p m$ & $H V$ & $D T$ & CSNRT & $\begin{array}{l}\text { Possible } \\
\text { aetiology }\end{array}$ \\
\hline M16 & + & Syncope & 4 & $-\star \star$ & 38 & - & 327 & Vasovagal* $^{\star}$ \\
M71 & + & Syncope & 12 & + & 36 & - & 154 & Unknown \\
M48 & - & Syncope & 16 & - & 62 & - & 1256 & Sinus arrest \\
M44 & - & Syncope & 20 & - & 50 & - & 642 & Unknown \\
M79 & + & Syncope & 6 & + & 47 & - & 429 & SVT‡ \\
M80 & + & SD & 10 & $-\star \star$ & 54 & - & 661 & VFף \\
\hline
\end{tabular}

DT, disopyramide test; pm, pacemaker; SVT, supraventricular tachycardia; VF, ventricular fibrillation. Other abbreviations as in DT, disopyramid 2

‡The patient had several witnessed syncopes of the vasovagal type during follow up.

$\star \star$ Declined pacemaker treatment.

tHolter recordings during follow up showed sinus arrests $>5 \mathrm{~s}$.

¥The patient had a documented supraventricular tachycardia with syncope the day after the electrophysiological study.

[Electrocardiogram recording showed ventricular fibrillation, dc shock ineffective. 
Table 4 The result of follow up for high degree atrioventricular block or bradycardia detected by a diagnostic pacemaker in 25 patients with synscope followed on average for 23.2 (SD 6.8) months (top), and 48 patients without syncope (bottom), followed on average for $23.8(6.4)$ months in relation to the result of the disopyramide test

\begin{tabular}{|c|c|c|c|c|}
\hline & $A V-I I I$ & $B D+$ & $\begin{array}{l}\text { No } A V-I I I \\
\text { or } B D+\end{array}$ & Total \\
\hline \multicolumn{5}{|c|}{ Syncope group } \\
\hline Positive DT & 5 & 0 & 3 & 8 \\
\hline Negative DT & 0 & 2 & 15 & 17 \\
\hline Total & 5 & 2 & 18 & 25 \\
\hline \multicolumn{5}{|c|}{ No syncope group } \\
\hline Positive DT & 1 & 2 & 1 & 4 \\
\hline Negative DT & 0 & 0 & 44 & 44 \\
\hline Total & 1 & 2 & 45 & 48 \\
\hline
\end{tabular}

AV-III, high degree atrioventricular block; $\mathrm{BD}+$, bradycardia detected by a diagnostic pacemaker (see text); DT, disopyramide test.

tive test, that is, a sensitivity of $100 \%$ in predicting this arrhythmia. One of the 45 nonsyncope patients without high degree atrioventricular block or bradycardia during follow up had a positive disopyramide test, that is, a specificity of $98 \%$.

A life table analysis showed a highly significant difference between patients with a negative and a positive disopyramide test with regard to impending high degree atrioventricular block or bradycardia ( $\mathrm{P}<0.001$ ) (figure).

\section{Discussion}

This study shows that the diagnostic yield of an invasive electrophysiological study in patients with bifascicular block can be significantly increased by using disopyramide as a pharmacological stress test. We also found that a positive disopyramide test is a rare finding in asymptomatic individuals who remain event-free during two years of follow up, indicating a high specificity.

\section{SENSITIVITY}

All patients with a documented, high degree atrioventricular block during follow up had a positive disopyramide test, that is, $100 \%$ sensitivity. Two patients with a negative test had a pacemaker detected bradycardia but had no atrioventricular block documented. This may have been because the follow up was too short
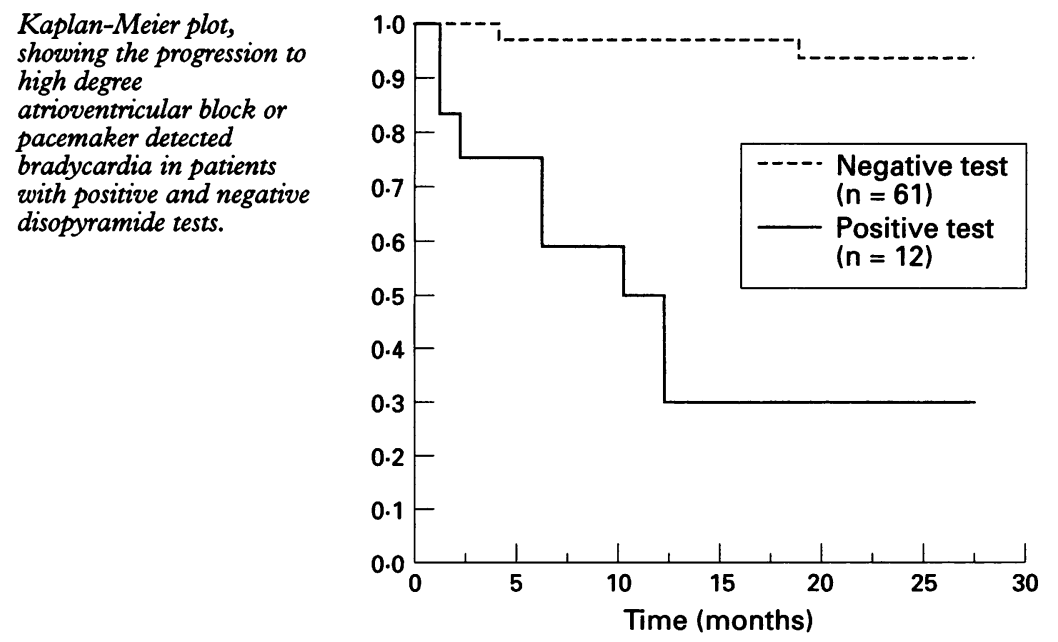

(14 and 26 months, respectively) or the visits too infrequent, or because of undersensing or other bradyarrhythmic mechanisms, such as sinus node dysfunction.

Since invasive electrophysiological testing presently is indicated only in symptomatic patients with bifascicular block, ${ }^{22}$ we assessed the sensitivity by using the syncope group. It is, however, important to note that all three patients in the non-syncope group who had high degree atrioventricular block or bradycardia during follow up had a positive disopyramide test.

\section{SPECIFICITY}

The specificity of the disopyramide test was previously unknown. By including a large control group of asymptomatic individuals who had similar clinical characteristics to those of the group of symptomatic patients, this study was specifically designed to address this issue. In order to define the specificity of a diagnostic and prognostic test, it is crucial to have a population truly devoid of the disorder studied. We defined this as patients in the non-syncope group who had no documented high degree atrioventricular block or bradycardia during follow up. It can be argued that this definition is too strict and that syncope patients without documented bradycardia during follow up should also be added to the asymptomatic population. This would, however, only marginally affect the specificity, with a decrease from $98 \%$ to $94 \%$.

PREVIOUS STUDIES ON ELECTROPHYSIOLOGICAL FINDINGS IN THE BASAL STATE

Like previous reports, ${ }^{46}$ this study shows that an electrophysiological study in a patient with bifascicular block is often inconclusive when performed in the basal state. Previous studies have shown conflicting results on the value of a prolonged $\mathrm{HV}$ interval in predicting progression to high degree atrioventricular block. ${ }^{467}$ Scheinman $e t a \bar{P}$ found that patients with an $\mathrm{HV}$ interval of more than $70 \mathrm{~ms}$ had a more than doubled risk. In our study, this finding had a high specificity but a low sensitivity. In accordance with previous studies, we found that His-Purkinje block during atrial pacing is a rare finding. ${ }^{81223}$

Programmed ventricular stimulation had a limited diagnostic yield in this study. Only 3\% had an inducible sustained monomorphic ventricular tachycardia, and we found no coexistence of bradyarrhythmias in these patients. It should, however, be emphasised that all patients had an ejection fraction of more than $35 \%$ and that the results would probably have been different in patients with left ventricular dysfunction.

\section{PREVIOUS STUDIES OF PHARMACOLOGICAL} PROVOCATION

Both procainamide and ajmaline have been used for pharmacological provocation of the His-Purkinje system in patients with bifascicular block. ${ }^{9-12}$ Owing to variations in dosages, variation in the criteria for a positive test, absence of adequate controls, and inconsisten- 
cies in the presentation of follow up data, comparisons between studies are difficult. A positive test was found in approximately $30 \%$ of patients with syncope, similar to our results. The sensitivity was $44 \%$ in predicting subsequent high degree atrioventricular block in one study, ${ }^{9}$ but the progression rate was too low to allow assessment of the predictive value in the others.

The first study of the use of disopyramide as a pharmacological stress test was a retrospective study, generating the criteria for a positive test used in the present study. ${ }^{14}$ An extension of that study proved the usefulness of the bradycardia-detecting pacemaker. ${ }^{15}$ Although the design and study populations differ substantially, the present prospective study confirms the high predictive value of the test.

\section{SHOULD ALL SYMPTOMATIC PATIENTS WITH BIFASCICULAR BLOCK BE PACED?}

There is no consensus in published reports about the evaluation and treatment of patients with bifascicular block and a history of unexplained syncope. In some textbooks the authors advocate permanent pacemaker treatment in all symptomatic patients, ${ }^{24}$ whereas others recommend an invasive electrophysiological study unless a significant bradycardia is documented. ${ }^{25-27}$ The first policy is supported by the fact that the risk of symptomatic bradycardia is eliminated without the cost of an invasive electrophysiological study. Several arguments, however, favour the second strategy. The annual progression rate to high degree atrioventricular block is low at $1-4 \%$, implying that a large number of patients will not need their pacemaker. Although modern pacemaker treatment is safe, it is certainly not free from complications and the patients are committed to lifelong treatment. Moreover, pacemaker treatment has not been shown to influence the mortality ${ }^{6}$ and, by not performing an electrophysiological study, other arrhythmias, such as ventricular tachycardia, might go undiagnosed. In the present study, the policy of pacing only patients with a positive disopyramide test would have resulted in pacemaker treatment in eight patients, in contrast to the 25 patients who would have received a pacemaker if the first policy had been applied. However, two patients with pacemakerdetected bradycardia but not documented high degree atrioventricular block would have been left untreated.

Thus it is our belief that permanent pacemaker treatment cannot be recommended to all symptomatic patients with bifascicular block on the basis of this study.

\section{LIMITATIONS}

Since we used a bradycardia-detecting pacemaker with only a ventricular lead, we could not differentiate between bradycardia due to intermittent atrioventricular block and atrial bradycardia. Although previous studies have shown a good relationship between pacemaker-detected bradycardia and subsequent development of high degree atrioventricular block, ${ }^{1517}$ a more recent study using dual chamber bradycardia-detecting pacemakers indicates that sinus bradycardia is also a common phenomenon in patients with suspected atrioventricular block. ${ }^{28}$

In order to minimise the risk for the asymptomatic volunteers, we applied strict exclusion criteria regarding impaired left ventricular function. This may raise doubts about the general applicability of the test to a symptomatic population. The majority of exclusions were because of an ejection fraction of $\leqslant 35 \%$. On the basis of previous experience of symptomatic patients, ${ }^{14}{ }^{15}$ this is probably too strict a criterion.

\section{CONCLUSIONS}

An invasive electrophysiological study in the basal state is often inconclusive in patients with bifascicular block and syncope. An HV interval of more than $70 \mathrm{~ms}$ and His-Purkinje block during atrial pacing are findings with a high specificity but low sensitivity for the prediction of impending high degree atrioventricular block. In patients without any of these findings, a pharmacological stress test should be considered. The disopyramide test has a high predictive value and a high specificity. Because it has a negative inotropic effect, the test should not be performed in patients with poor left ventricular function.

1 Schneider JF, Thomas HE, Kreger BE, McNamara PM, Sorlie P, Kannel WB. Newly acquired right bundle branch block: the Framingham Study. Ann Intern Med 1980;92:37-44.

2 Schneider JF, Thomas HE, Kreger BE, McNamara PM, Kannel WB. Newly acquired left bundle branch block: the Framingham Study. Ann Intern Med 1979;90:303-10.

3 McAnulty JH, Rahimtoola SH. Bundle branch block. Prog Cardiovasc Dis 1983;26:333-54.

4 Dhingra RC, Palileo E, Strasberg B, Swiryn S, Bauernfeind RA, Wyndham C, et al. Significance of the HV interval in 517 patients with chronic bifascicular block. Circulation 517 patients with

5 Scheinman MM, Peters RW, Sauvé MJ, Desai J, Abbott $\mathrm{JA}$, Cogan J, et al. Value of the H-Q interval in patients with bundle branch block and the role of prophylactic permanent pacing. Am f Cardiol 1982;50:1316-22.

6 McAnulty JH, Rahimtoola SH, Murphy E, DeMotes H Ritzmann L, Kanarek PE, et al. Natural history of "high risk" bundle branch block. Final report of a prospective study. N Engl ₹ Med 1982;307:137-43.

7 Scheinman MM, Peters RW, Morady F, Sauvé MJ, Malone P, Modin G. Electrophysiologic studies in patients with bundle branch block. PACE 1983, 6:1157-65.

8 Dhingra RC, Wyndham C, Bauernfeind RA, Swiryn S, Deedwania PC, Smith T, et al. Significance of block distal to His bundle induced by atrial pacing in patients with

chronic bifascicular block. Circulation 1979;60:1455-64. Poupet JY, Allal J, Vieyres C, Gallimard JF, Coisne D Barraine R. Evolution à 5 ans des blocs de branches chroniques chez 164 patients appareillés par stimulateu sans bloc auriculo-ventriculaire spontane documenté Etude des critères prédictifs. Arch Mal Caur

10 Kaul U, Dev V, Narula J, Malhotra A, Talwar KK, Bhatia ML. Evaluation of patients with bundle branch block and "unexplained syncope": a study based on comprehensive electrophysiologic testing and Ajmaline test. PACE 1988, 11:289-96.

11 Twidale N, Heddle WF, Tonkin AM. Procainamide administration during electrophysiology study-utility as a provocative test for intermittent atrioventricular block. PACE 1988;11:1388-97.

12 Click RL, Gersh BJ, Sugrue DD, Holmes DR, Wood DL Osborn MJ, et al. Role of invasive electrophysiologic testing in patients with symptomatic bundle branch block. Am $\mathcal{F}$ Cardiol 1987;59:817-23.

13 Ezri $M$, Lerman BB, Marchilinski FE, Buxton AE, Josephson ME. Electrophysiologic evaluation of syncope in patients with bifascicular block. Am Heart $\mathcal{f} 1983$ 106:693-7.

14 Bergfeldt L, Rosenqvist $M$, Vallin $H$, Edhag $O$. tricular block in patients with bifascicular block. An acute tricular block in patients with bifascicular block. An acute Br Heart $₹$ 1985;53:328-34. 
15 Bergfeldt L, Edvardsson N, Rosenqvist M, Vallin H, Edhag $O$. Atrioventricular block progression in patients with bifascicular block assessed by repeated electrocardiography and bradycardia detecting pacemaker. $A m \mathcal{F}$ Cardio 1994;74:1129-32.

16 Schiller NB, Shah PM, Crawford M, DeMaria A, Devereux $R$, Feigenbaum $H$, et al. Recommendations for quantificaraphy. $\mathcal{F}$ Am Soc Echo 1989;2:358-67.

17 Rosenqvist M, Edhag O, Vallin H. Clinical experience with a bradycardia indicating pacemaker. PACE 1983;6: a brady

18 Criteria Committee of the New York Heart Association. In Nomenclature and criteria for diagnosis of diseases of the hear and great vessels. Boston: Boston, Little, Brown and Company, 1973:238-9.

19 Shapiro S, Wilk M. An analysis variance test for normality (complete samples). Biometrika 1965;52:591-611.

20 Galen RS, Gambino SR. Beyond normality. The predictive value and efficiency of medical diagnosis. New York: John Wiley, 1975:9-14.

21 Kaplan EL, Meier P. Nonparametric estimation from incomplete observations. $\mathcal{F} \mathrm{Am}$ Stat Assoc 1958;53: 457-81.

22 Zipes DP, Akhtar M, Denes P, DeSanctis R, Garson A Gettes $L S$, et al. Guidelines for clinical intracardiac Gectrophysic College of Cardiology/American Heart Association-
Task force on assessment of diagnostic and therapeutic cardiovascular procedures (subcommittee to assess clinical intracardiac electrophysiologic studies). $7 \mathrm{Am}$ Coll Cardiol 1989;14:1827-42.

23 Morady F, Higgins J, Peters RW, Schwartz AB, Shen EN, Bhandari A, et al. Electrophysiologic testing in bundle branch block and unexplained syncope. Am $\mathrm{f}$ Cardiol 1984;54:587-91.

24 Ward DE, Camm J. Atrioventricular conduction delays and block. In: Ward DE, Camm J, ed. Clinical electrophysiology of the heart. London: Edward Arnold, 1987 . physiolo

25 Danforth J, Goldschlager N. Indications for cardiac pacing in the adult. In: Saksena S, Goldschlager N, ed. Electrical in the adult. In: Saksena S, Goldschlager N, ed. Electrical
therapy for cardiac arrhythmias. Philadelphia: WB therapy for cardiac arrhythmias.

26 Sutton R. Syncope. In: Julian DG, Camm AJ, Fox KM, Hall RJC, Poole-Wilson PA, ed. Diseases of the heart London: Baillière Tindall, 1989:1431-9.

27 Tolentino AO, Javier RP, Samet P. Indications for cardiac pacing in bradyarrhythmias. In: El-Sherif N, Samet P, ed. Cardiac pacing and electrophysiology. Philadelphia: WB Saunders, 1991:652-61.

28 Barnay C, Frank R, Lascault G, Himbert C, Cazeau S, Medvedowsky JL. Diagnostic functions in cardiac pacemakers implanted for unexplained syncopes. In: Adornato $\mathrm{E}, \mathrm{Galassi} \mathrm{A}$, ed. How to approach cardiac arrhythmias in 1994. Taormina: Edizioni Luigi Pozzi, 1994:376-84. 